\title{
Increased biomass production and glycogen accumulation in apcE gene deleted Synechocystis sp. PCC 6803
}

Ancy Joseph ${ }^{1 \dagger}$, Shimpei Aikawa ${ }^{1,2+}$, Kengo Sasaki ${ }^{3}$, Fumio Matsuda ${ }^{4,5}$, Tomohisa Hasunuma 3,6 and Akihiko Kondo ${ }^{1,5,7^{*}}$

\begin{abstract}
The effect of phycobilisome antenna-truncation in the cyanobacterium Synechocystis sp. PCC 6803 on biomass production and glycogen accumulation have not yet been fully clarified. To investigate these effects here, the apcE gene, which encodes the anchor protein linking the phycobilisome to the thylakoid membrane, was deleted in a glucose tolerant strain of Synechocystis sp. PCC 6803. Biomass production of the apcE-deleted strain under photoautotrophic and atmospheric air conditions was 1.6 times higher than that of strain PCC $6803(1.32 \pm 0.01$ versus $0.84 \pm 0.07 \mathrm{~g}$ cell-dry weight $\mathrm{L}^{-1}$, respectively) after 15 days of cultivation. In addition, the glycogen content of the apcE-deleted strain $(24.2 \pm 0.7 \%)$ was also higher than that of strain PCC $6803(11.1 \pm 0.3 \%)$. Together, these results demonstrate that antenna truncation by deleting the apcE gene was effective for increasing biomass production and glycogen accumulation under photoautotrophic and atmospheric air conditions in Synechocystis sp. PCC 6803.
\end{abstract}

Keywords: Cyanobacteria; Antenna truncation; Biomass production; Glycogen; Synechocystis sp. PCC 6803

\section{Introduction}

Biorefinery processes that convert sustainable biomass into commercially valuable chemical and energy sources have received increasing attention because of depleting fossil fuel reserves and concerns about the accumulation of greenhouse gases (Hasunuma et al. 2013a). Recently, microalgae and cyanobacteria have been utilized as feedstocks for biorefinery processes, to produce third-generation fuels, due to their high photosynthetic efficiency compared with sugar or starch crops such as sugar cane and corn, and $\mathrm{CO}_{2}$-neutral fuel production (Schenk et al. 2008; Nguyen et al. 2012; Aikawa et al. 2013). For example, bioethanol was produced directly from the cyanobacterium Arthrospira platensis, which contains high levels of storage glycogen, by a recombinant yeast strain diplaying an amylolytic enzyme (Aikawa et al. 2013). To further increase the production of energy and valuable chemical

\footnotetext{
* Correspondence: akondo@kobe-u.ac.jp

${ }^{\dagger}$ Equal contributors

'Department of Chemical Science and Engineering, Graduate School of Engineering, Kobe University, 1-1 Rokkodaicho, Nada-ku, Kobe, Hyogo 657-8501, Japan

${ }^{5}$ RIKEN Biomass Engineering Program, 1-7-22 Suehirocho, Tsurumi, Yokohama 230-0045, Japan

Full list of author information is available at the end of the article
}

products using these biorefinery processes, it is necessary to increase the mass productivity and carbohydrate content such as glycogen of oxygenic photosynthetic microorganisms.

At high light intensities, the rate of photon absorption by the chlorophyll antenna molecules in the surface layer of microalgal and cyanobacterial cells in cultures or pond environments exceeds the rate of photosynthetic reactions, resulting in the dissipation or loss of excess photons and/or photoinhibition of photosynthesis (Melis 2009). In addition, as a result of this excess photon absorption by surface-layer cells, cells at greater distances from the surface are deprived of sufficient light to support photosynthesis (Melis 2009). However, it was shown that a truncated chlorophyll antenna mutant of the green alga Chlamydomonas reinhardtii exhibited reduced absorbance of light by the first layers of cells and alleviated photoinhibition, resulting in high biomass production (Polle et al. 2003).

The cyanobacterium Synechocystis sp. PCC 6803 has been widely studied as a model species for photosynthetic processes because of its transformability and full sequenced genome (Kaneko et al. 1996). Synechocystis sp. PCC 6803 have a large membrane-extrinsic phycobilisome antenna, which is composed of rods of the pigment phycocyanin, 
an allophycocyanin core, and several linker proteins connecting the rods to the core and the core to the thylakoid membrane (MacColl 1998). However, truncation of phycobilisome antenna by deleting phycocyanin rods or the entire phycobilisome assembly decreases biomass productivity under atmospheric air or $5 \% \mathrm{CO}_{2}$ bubbling conditions (Page et al. 2012). On the other hand, previous studies have shown that deletion of apcE gene, whose product is involved in the interection between the thylakoids and phycobilisome (Shen et al. 1993), leads to the loss of phycobilins from the thylakoid fraction and decrease in antenna size (Shen et al. 1993; Ajlani et al. 1995). Deletion of apcE gene resulted in decreased biomass production under photoautotrophic and undefined $\mathrm{CO}_{2}$ conditions (Shen et al. 1993). To date, therefore, the effect of $a p c E$ deletion on biomass production has not been fully investigated.

In this study, the effect of $a p c E$ gene deletion on the growth of Synechocystis sp. PCC 6803 was investigated under photoautotrophic conditions with atmospheric air, $1 \% \mathrm{CO}_{2}$, or $2 \% \mathrm{CO}_{2}$. In addition, the effect of apcE gene deletion on glycogen accumulation was also investigated. Atmospheric $\mathrm{CO}_{2}$ condition was effective to increase biomass production and glycogen accumulation in $a p c E$ gene deleted Synechocystis sp. PCC 6803.

\section{Materials and methods}

\section{Microorganisms and growth condition}

A glucose-tolerant strain of Synechocystis sp. PCC 6803 (here after referred to as GT) was obtained from Prof. Masahiko Ikeuchi of the University of Tokyo. Synechocystis sp. PCC 6803 was routinely cultured in BG11 medium, which contained $1.5 \mathrm{~g} \mathrm{~L}^{-1} \mathrm{NaNO}_{3}, 0.04 \mathrm{~g} \mathrm{~L}^{-1} \mathrm{~K}_{2} \mathrm{HPO}_{4}$, $0.075 \mathrm{~g} \mathrm{~L}^{-1} \mathrm{MgSO}_{4} \cdot 7 \mathrm{H}_{2} \mathrm{O}, 36 \mathrm{mg} \mathrm{L}{ }^{-1} \mathrm{CaCl}_{2} \cdot 2 \mathrm{H}_{2} \mathrm{O}$, $6 \mathrm{mg} \mathrm{L}^{-1}$ citric acid, $6 \mathrm{mg} \mathrm{L}^{-1}$ ferric ammonium citrate, $1 \mathrm{mg} \mathrm{L}^{-1}$ EDTA (disodium salt), $20 \mathrm{mg} \mathrm{L}^{-1} \mathrm{NaCO}_{3}$, $2.86 \mathrm{mg} \mathrm{L}^{-1} \mathrm{H}_{3} \mathrm{BO}_{3}, 1.81 \mathrm{mg} \mathrm{L}^{-1} \mathrm{MnCl}_{2} \cdot 4 \mathrm{H}_{2} \mathrm{O}$, $0.222 \mathrm{mg} \mathrm{L}^{-1} \mathrm{ZnSO}_{4} \cdot 7 \mathrm{H}_{2} \mathrm{O}, 0.39 \mathrm{mg} \mathrm{L}^{-1} \mathrm{NaMoO}_{4}$. $2 \mathrm{H}_{2} \mathrm{O}, 0.079 \mathrm{mg} \mathrm{L}^{-1} \mathrm{CuSO}_{4} \cdot 5 \mathrm{H}_{2} \mathrm{O}$, and $49.4 \mu \mathrm{g} \mathrm{L}^{-1} \mathrm{Co}$ $\left(\mathrm{NO}_{3}\right)_{2} \cdot 6 \mathrm{H}_{2} \mathrm{O}$ (Rippka 1988), under continuous illumination at 50 or $200 \mu \mathrm{mol}$ photons $\mathrm{m}^{-2} \mathrm{~s}^{-1}$ using white fluorescence bulbs (Life Look HGX and NHG; NEC, Tokyo, Japan) at $28 \pm 2^{\circ} \mathrm{C}$ under atmospheric air conditions. For $\mathrm{CO}_{2}$ enriched cultivation, cells were cultivated at $50 \mu \mathrm{mol}$ photons $\mathrm{m}^{-2} \mathrm{~s}^{-1}$ and 1 or $2 \% \mathrm{CO}_{2}$ was supplied

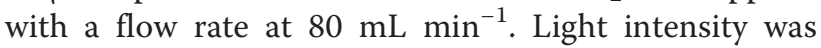
measured in the middle of the culture using an LI-250A light meter (LI-COR, Lincoln, NE) equipped with an LI190SA quantum sensor (LI-COR). Escherichia coli strain $\mathrm{DH} 5 \alpha$ was used to propagate pBluescriptSK- and the apcE inactivation plasmids.

\section{Cloning and transformation}

For the construction of an apcE mutant, the 500-bp upstream and downstream regions of the $a p c E$ (slr0335) coding region of GT were isolated by PCR using the primers listed in Additional file 1: Table S1. The obtained DNA fragments were joined through standard PCR-driven overlap extension to form a single DNA segment harbouring a AatII restriction site in place of the coding region. After cloning the fused DNA fragment into pBluescriptSK, the resulting plasmids were digested with AatII, and an AatII-digested $\mathrm{Km}^{\mathrm{r}}$ cassette, which was amplified from the $\mathrm{pCR}^{\odot}$ II-Blunt$\mathrm{TOPO}^{\circledR}$ vector (Toyobo Life science, Japan) was ligated into the plasmid in the same orientation as the coding region. The resulting deletion cassette was verified by PCR and nucleotide sequencing (Big Dye kit, ABI Perking Elmer). For the selection and maintenance of plasmids, the culture medium was supplemented with $50 \mu \mathrm{g} \mathrm{L}^{-1}$ of kanamycin. The vector containing the deletion casette was transformed into GT by homologous recombination and positive colonies were identified by PCR analysis. Selected clones were restreaked on plates supplemented with appropriate antibiotics to obtain complete deletion of the apcE gene. The apcE gene-disrupted GT mutant ( $\triangle a p c E$ mutant) was routinely cultivated in BG11 medium supplemented with $50 \mu \mathrm{g} \mathrm{L}^{-1}$ of kanamycin under the same conditions used for GT, unless otherwise mentioned.

\section{Spectral analysis}

After cultivation of GT for 9 days under the conditions described above, the culture was diluted with fresh medium to adjust the $\mathrm{OD}_{750}$ to 0.1 . Steady-state absorption spectra were collected at room temperature using a spectrometer equipped with an integrating sphere (JASCO V-650/ISV-722), as described previously (Akimoto et al. 2013). All absorption spectra were normalized to the chlorophyll Qy band ( 676 nm).

\section{Analytical methods}

Cell growth was monitored tubidimetrically by measuring $\mathrm{OD}_{750}$. Cell concentration in culture media is reported as dry cell weight, as a linear correlation was obtained between dry cell weight and optical density. It was determined that $1.0 \mathrm{OD}_{750}$ equals approximately $0.26 \mathrm{~g}$ dry-cell weight $\mathrm{L}^{-1}$ both in GT and $\triangle a p c E$ mutant.

The total carbohydrate content was analyzed by a colorimetric method using anthrone reagent (Updegraff 1969). Briefly, $5 \mathrm{mg}$ of algal powder was reacted in $75 \%$ sulfuric acid containing $2 \mathrm{~g} \mathrm{~L}^{-1}$ anthrone reagent for $15 \mathrm{~min}$ at $100^{\circ} \mathrm{C}$. The absorbance of the resulting solution and glucose as standard was measured at $620 \mathrm{~nm}$. Total protein content was extracted from $5 \mathrm{mg}$ of cells as described previously (De Marsac and Houmard 1988). Protein concentrations were determined using a Sigma QuantiPro BCA Assay Kit (Sigma-Aldrich, St Louis, MO, USA) as directed by the manufacturer's protocol and using bovine serum albumin as a standard. Glycogen content was determined by high-performance liquid chromatography 
(HPLC) (Shimadzu, Kyoto, Japan) using a size exclusion HPLC column (OHpak SB-806 M HQ; Shodex, Tokyo, Japan) and a reflective index detector (RID-10A; Shimadzu) as described previously (Izumi et al. 2013). Glycogen was extracted from the dried cells using a previously reported method with slight modifications (Ernst et al. 1984). The cells used for the assay were collected by centrifugation at $6,300 \times g$ for $2 \mathrm{~min}$ at $25 \pm 2^{\circ} \mathrm{C}$ and washed once with $0.3 \mathrm{M}$ ammonium carbonate, which was volatilized during the subsequent lyophilisation process.

Photosynthetic oxygen evolution by the cells was determined in the exponential growth phase with a Clark-type oxygen electrode (DW2/2, Hansatech Instruments Ltd., King's Lynn, UK) controlled by a computerized oxygen monitoring system (OMS; Hansatech Instruments Ltd.). After system calibration, photosynthetic $\mathrm{O}_{2}$ evolution was monitored for $8 \mathrm{~min}$ at $30^{\circ} \mathrm{C}$ during irradiation at 50, 100, 200, 300, 600, 1200, $1800 \mu \mathrm{mol}$ photons $\mathrm{m}^{-2} \mathrm{~s}^{-1}$ from a halogen light source. Cell concentration in the reaction mixture was adjusted to an $\mathrm{OD}_{750}$ of 1.0 with $\mathrm{BG} 11$ medium.

\section{Results}

\section{Construction of an $\triangle a p c E$ mutant}

Complete deletion of the $a p c E$ gene was confirmed by PCR analysis using the primers designed to bind $500 \mathrm{bp}$ upstream and downstream of the $a p c E$ gene, as listed in Additional file 1: Table S1. The $\triangle a p c E$ mutant gave a single amplicon of $2.0 \mathrm{~kb}$, confirming the deletion of the apcE gene and insertion of the kanamycin cassette, whereas GT produced an amplicon of $3.6 \mathrm{~kb}$ corresponding to the $a p c E$ gene (Figure 1a).

\section{Absorption spectra of GT and $\triangle a p c E$ mutant}

For a quantitative analysis of the spectral features of GT and the $\triangle a p c E$ mutant, absorption spectra of intact cells were measured (Figure 1b). All absorption spectra were normalized at the chlorophyll Qy band. The absorption spectra of GT showed four peaks, which were assigned to the chlorophyll Soret $(\sim 435 \mathrm{~nm})$, carotenoid $(\sim 500 \mathrm{~nm})$, phycobilisome $(\sim 620 \mathrm{~nm})$, and chlorophyll Qy $(\sim 676 \mathrm{~nm})$ bands based on a previous report (Akimoto et al. 2013). The $\triangle a p c E$ mutant showed a large reduction in the 620-nm absorption maximum of GT, as was previously observed for a phycobiliprotein-less mutant of Synechocystis sp. PCC 6803 (Shen et al. 1993; Ajlani and Vernotte 1998). The relative amount of chlorophyll (chlorophyll Soret and chlorophyll Qy) in the $\triangle a p c E$ mutant and wild-type GT were similar. These results suggested that deletion of the apcE gene, which would have impaired phycobilisome assembly and attachment, does not affect the amount of chlorophyll in cells.

\section{Effect of apcE gene deletion on growth of GT}

To determine the impact of minimizing phycobilisome antenna size through deletion of the apcE gene on photoautotrophic growth, GT and the $\triangle a p c E$ mutant were grown under atmospheric air conditions. Under these conditions, biomass production of the $\triangle a p c E$ mutant, as determined from $\mathrm{OD}_{750}$, was approximately 1.6-fold higher than that of GT after 15 days of cultivation with $50 \mu \mathrm{mol}$ photons $\mathrm{m}^{-2} \mathrm{~s}^{-1}$ illumination $(0.84 \pm 0.07$ and $1.32 \pm$ 0.01 g-cell-dry weight $\mathrm{L}^{-1}$ for GT and the $\triangle a p c E$ mutant, respectively) (Figure 2). When the light intensity was increased to $200 \mu \mathrm{mol}$ photons $\mathrm{m}^{-2} \mathrm{~s}^{-1}$ under atmospheric
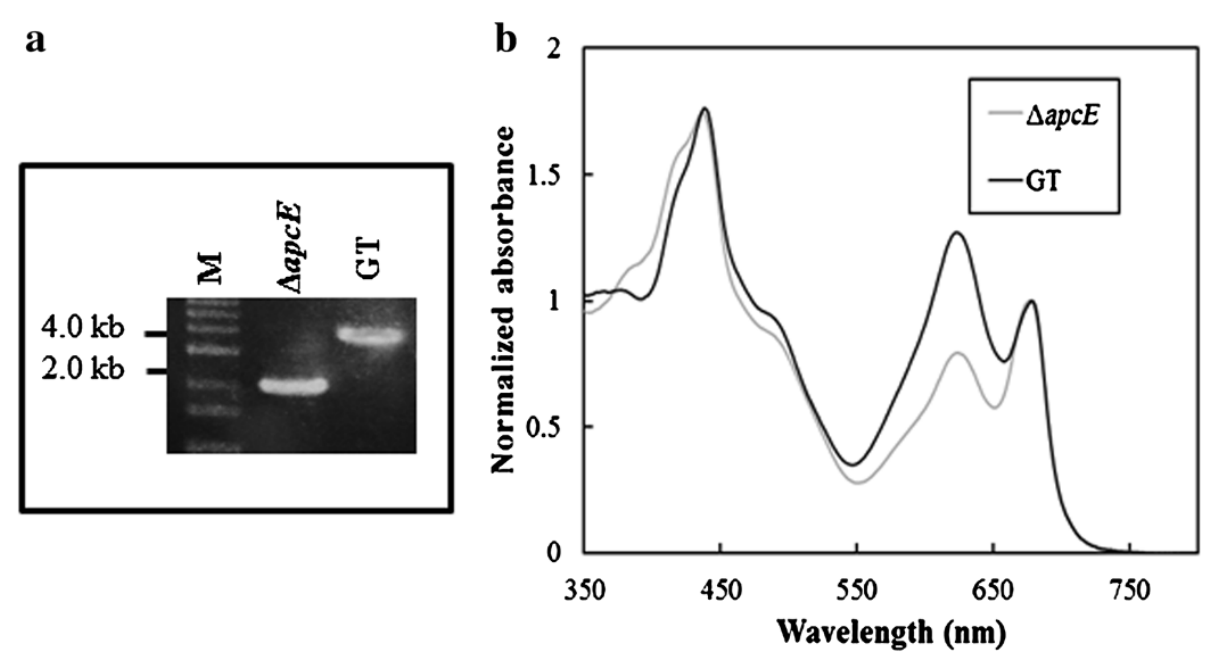

Figure 1 Confirmation of complete deletion of the apcE gene. (a) PCR with primers flanking the apcE gene for $\triangle a p c E$ mutant (Lane 2) and glucose-tolerant Synechocystis sp. PCC 6803 (GT) (Lane 3). Lane 1 is DNA size marker (M). (b) Absorption spectral analysis of GT (black line) and $\triangle a p c E$ (grey line). 


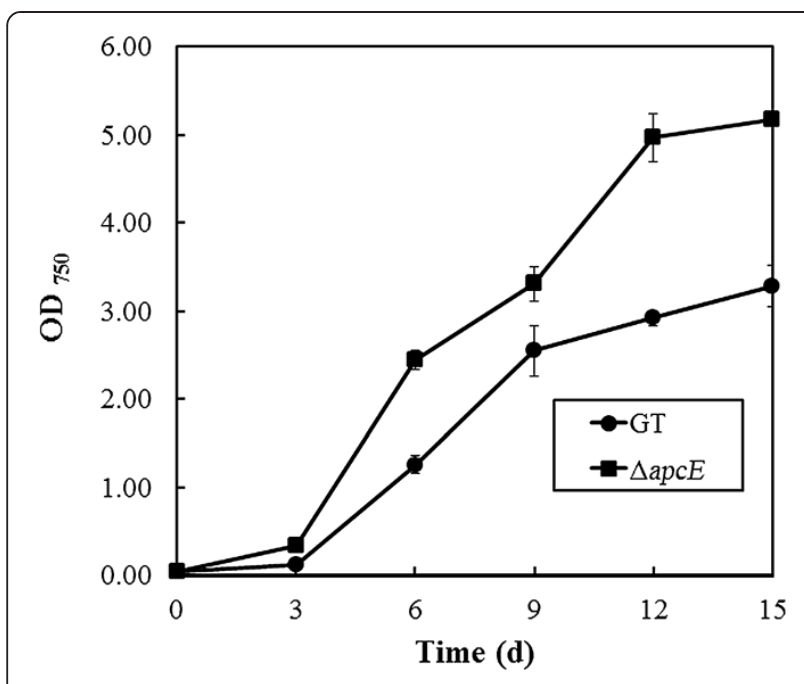

Figure 2 Growth curves of glucose-tolerant Synechocystis sp. PCC 6803 (GT) (closed circles) and the $\triangle a p c E$ mutant (closed squares) under photoautotrophic and atmospheric air conditions with illumination at 50 mol photons $\mathrm{m}^{-2} \mathrm{~s}^{-1}$. Error bars represent the mean of triplicate experiments.

air condition, biomass production of the $\triangle a p c E$ mutant was higher than that of GT during 15 days of cultivation (Figure 3). However, under photoautotrophic $(50 \mu \mathrm{mol}$ photons $\mathrm{m}^{-2} \mathrm{~s}^{-1}$ illumination) and $1 \% \mathrm{CO}_{2}$ condition, $\triangle a p c E$ mutant showed weak growth during 15 days of cultivation (Figure 4). In addition, the $\triangle a p c E$ mutant showed no growth by elevating $\mathrm{CO}_{2}$ to $2 \%$, whereas the GT showed growth (data not shown). Deletion of the apcE gene caused a colour change as observed in the $\triangle a p c E$

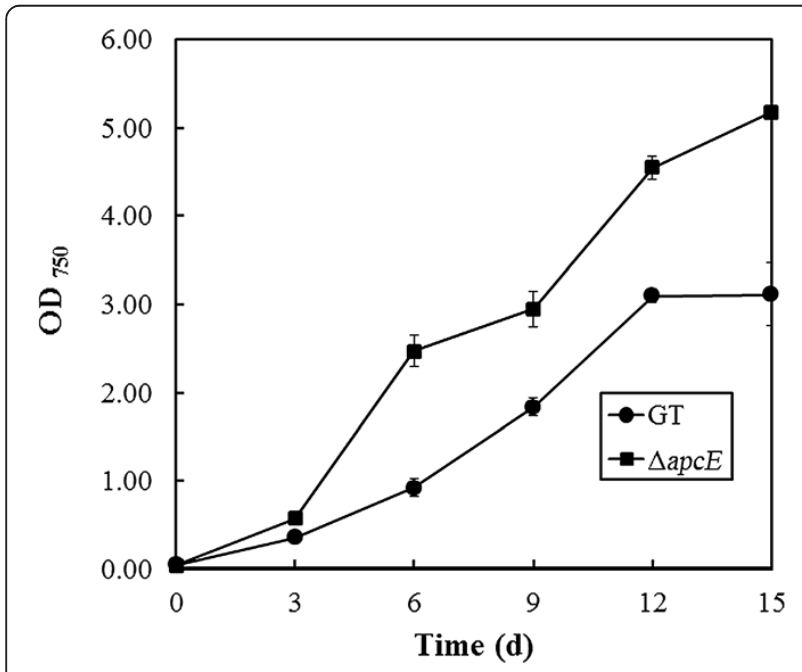

Figure 3 Growth curves of glucose-tolerant Synechocystis sp. PCC 6803 (GT) (closed circles) and the $\triangle a p c E$ mutant (closed squares) under photoautotrophic and atmospheric air conditions with illumination at $\mathbf{2 0 0} \boldsymbol{\mu m o l}$ photons $\mathrm{m}^{-2} \mathrm{~s}^{-1}$. Error bars represent the mean of triplicate experiments.

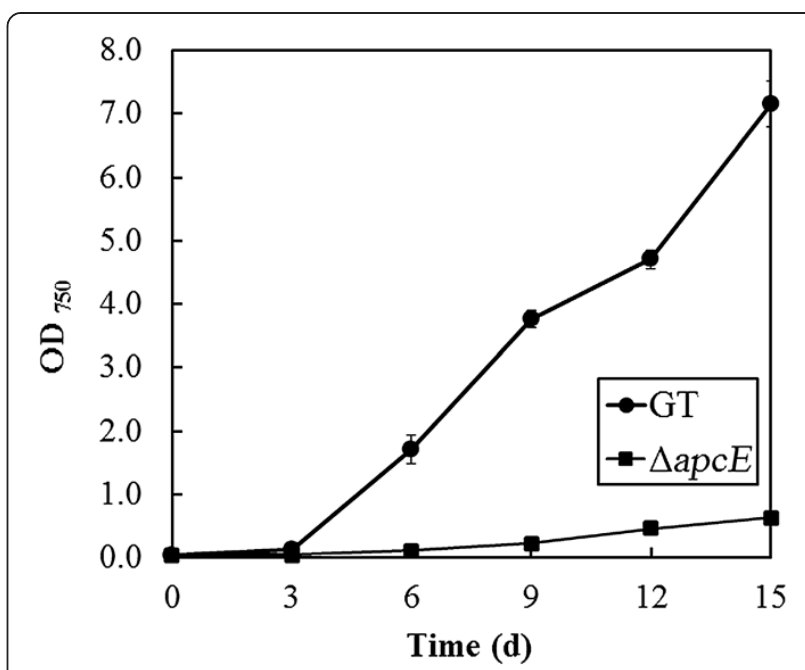

Figure 4 Growth curves of glucose-tolerant Synechocystis sp. PCC 6803 (GT) (closed circles) and the $\triangle a p c E$ mutant (closed squares) under photoautotrophic and $1 \% \mathrm{CO}_{2}$ conditions with illumination at $50 \mu \mathrm{mol}$ photons $\mathrm{m}^{-2} \mathrm{~s}^{-1}$. Error bars represent the mean of triplicate experiments.

mutant. The $\triangle a p c E$ mutant appeared olive green in colour due to a reduction in the amount of phycocyanin, as reported previously (Ajlani et al. 1995), whereas GT cell appeared blue-green in colour.

\section{Cell compositions of GT and $\triangle a p c E$ mutant}

To investigate the effect of $a p c E$ deletion on cell composition under photoautotrophic and atmospheric air conditions, carbohydrate and protein contents were analysed in GT and the $\triangle a p c E$ mutant after 15 days of cultivation with $50 \mu \mathrm{mol}$ photons $\mathrm{m}^{-2} \mathrm{~s}^{-1}$ illumination (Table 1). The protein and carbohydrate contents in the $\triangle a p c E$ mutant were similar with those in GT, showing that $a p c E$ deletion did not affect protein and carbohydrate levels. However, in GT, only an average of $42.0 \pm 0.3 \%$ of available carbohydrate was converted to glycogen, whereas the $\triangle a p c E$ mutant converted $85.0 \pm 4.8 \%$ of carbohydrate to glycogen. Glycogen accumulation in the $\triangle a p c E$ mutant corresponded to approximately $24 \%$ of total dry cell weight after 15 days of cultivation, whereas the accumulated glycogen in GT

Table 1 Biochemical composition of glucose-tolerant Synechocystis sp. PCC 6803 (GT) and the $\triangle$ apcE mutant under photoautotrophic and atmospheric air conditions with illumination at $50 \mu \mathrm{mol}$ photons $\mathrm{m}^{-2} \mathrm{~s}^{-1}$ on day 15

\begin{tabular}{|c|c|c|c|c|}
\hline \multirow[t]{2}{*}{ Strain } & \multirow[t]{2}{*}{$\begin{array}{l}\text { Dry-cell } \\
\text { weight }\left(\mathrm{g} \mathrm{L}^{-1}\right)\end{array}$} & \multirow[t]{2}{*}{$\begin{array}{l}\text { Protein (\% in } \\
\text { dry-cell weight) }\end{array}$} & \multicolumn{2}{|c|}{$\begin{array}{l}\text { Carbohydrate } \\
\text { (\% in dry-cell weight) }\end{array}$} \\
\hline & & & Glycogen & Others \\
\hline$\overline{\mathrm{GT}}$ & $0.84 \pm 0.07$ & $47.3 \pm 2.5$ & $11.1 \pm 0.3$ & $15.4 \pm 0.5$ \\
\hline$\triangle a p c E$ & $1.32 \pm 0.01$ & $48.4 \pm 0.2$ & $24.2 \pm 0.7$ & $4.3 \pm 1.5$ \\
\hline
\end{tabular}

Data are presented as the mean and standard deviation of three individual experiments. 
cells corresponded to only $11 \%$ of dry cell weight (Table 1 ). At $200 \mu \mathrm{mol}$ photons $\mathrm{m}^{-2} \mathrm{~s}^{-1}$ illumination and photoautotropic air condition, the glycogen content as a fraction of total dry cell weight was higher in the $\triangle a p c E$ mutant $(25.8 \pm 0.2 \%)$ than that of GT $(18.5 \pm 0.1 \%)$. These results showed that the restriction of photoantennae size directed carbon flux towards glycogen accumulation under photoautotrophic and atmospheric air conditions.

\section{Effect of apcE gene deletion on photosynthesis}

The rate of oxygen evolution under in-vivo conditions with photoautotrophically grown cells of GT and the $\triangle a p c E$ mutant under different light intensities and atmospheric air condition was measured to generate light-photosynthesis curve (Figure 5). The rate of oxygen evolution by GT and $\triangle a p c E$ mutant cells at 50,100, 200 and $300 \mu \mathrm{mol}$ photons $\mathrm{m}^{-2} \mathrm{~s}^{-1}$ were similar, suggesting that the efficiency of photon use was similar by the two strains under these light conditions. However, the rate of oxygen evolution at 600 , $1200,1800 \mu \mathrm{mol}$ photons $\mathrm{m}^{-2} \mathrm{~s}^{-1}$ was higher in the $\triangle a p c E$ mutant than that in GT, suggesting that the light-saturated evolution $\left(P_{\max }\right)$ was higher in $\triangle a p c E$ mutant. This result was consistent with the previous finding that the green alga Chlamydomonas reinhardtii with a truncated chlorophyll antenna has an increased $P_{\max }$ (Polle et al. 2003).

\section{Discussion}

In this study, reducing the chlorophyll antenna size of the photosystems through mutation of the $a p c E$ gene in Synechocystis sp. PCC 6803 led to increased productivity, as determined by the increase in cell density under photoautotrophic and low $\mathrm{CO}_{2}$ conditions $(0.04 \%$ in atmospheric air). The $\triangle a p c E$ mutant has a similar doubling time as the

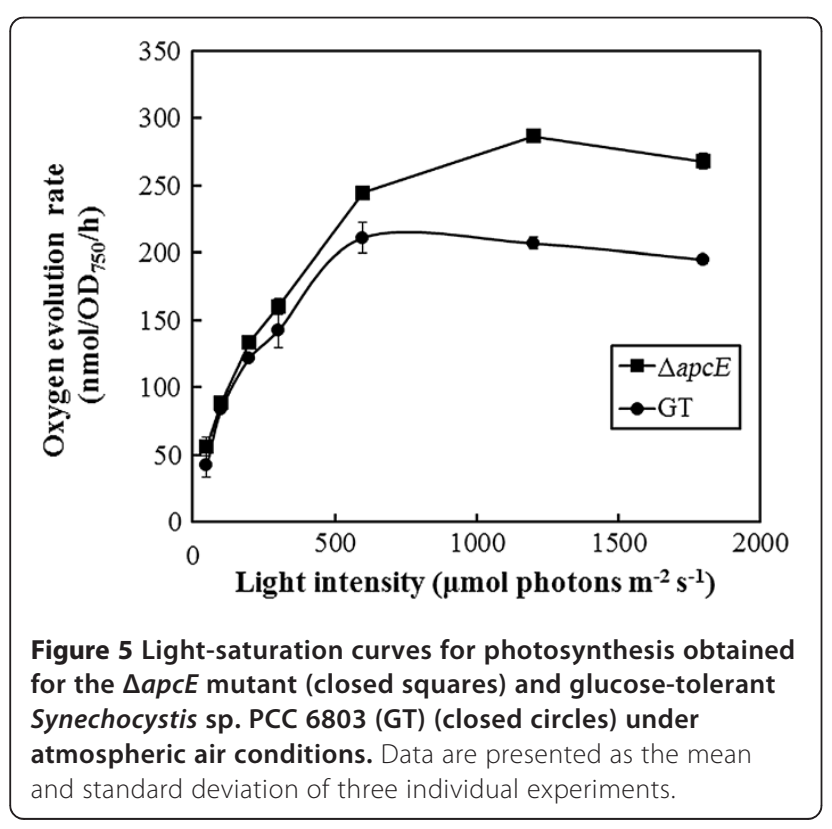

glucose-tolerant strain of Synechocystis sp. PCC 6803 $(21.25 \pm 0.55 \mathrm{~h}$ and $24.88 \pm 0.81 \mathrm{~h}$ for $\mathrm{GT}$ and $\triangle a p c E$ mutant, respectively), between 3 to 6 days of culture. These doubling times are similar to that $(25.2 \mathrm{~h})$ reported previously for wild-type Synechocystis sp. cells (Page et al. 2012). Deletion of the $\triangle a p c E$ gene increased the maximum cell density of cultures due to the decreased absorption of light by cells at the surface layer. Previous investigations by Nakajima and Ueda (1997) and Bernát et al. (2009) showed that the growth rate of a Synechocystis $\triangle a p c E$ mutant was slower than that of the wild-type strain under photoautotrophic conditions with $1 \% \mathrm{CO}_{2}$, which corresponded with our results (Figure 4). Together, these findings suggest that the presence of high concentrations of $\mathrm{CO}_{2}$ might reduce the growth of $\triangle a p c E$ mutants. Although the reason behind this phenomenon is presently unclear, metabolic and gene expression analysis are expected to provide insight into this response and are currently underway in our laboratory. Under air conditions with illumination at 50 and $200 \mu \mathrm{mol}$ photons $\mathrm{m}^{-2} \mathrm{~s}^{-1}$, the photosynthetic acitivities of the $\triangle a p c E$ mutant and wild-type strain were similar, as judged from the rate of oxygen evolution, although biomass production was higher in the $\triangle a p c E$ mutant, which was shown to markedly decreased levels of phycobilisomes. Thus, under photoautotrophic and low $\mathrm{CO}_{2}$ conditions, absorbed $\mathrm{CO}_{2}$ would be utilized by the $\triangle a p c E$ mutant for cell growth, rather than the production of phycobilisomes.

The accumulation of glycogen in cyanobacterial cells, which are attractive feedstocks for biorefinery processes (Aikawa et al. 2013), was also increased in the $\triangle a p c E$ mutant compared with wild-type cells under photoautotrophic and atmospheric air conditions. In light conditions, cyanobacteria fix $\mathrm{CO}_{2}$ via the Calvin-Benson-Bassham (CBB) cycle, and CBB cycle intermediates enter central metabolic pathways, such as glycolysis and the tricarboxylic acid (TCA) cycle, and that leading to glycogen synthesis (Li and Liao 2013). Glycogen synthesis is the major carbon and energy storage pathway, whereas glycolysis and the TCA cycle produce building blocks for cell growth. During prolonged nitrogen starvation, Synechocystis sp. PCC 6803 stores glycogen and degrades nitrogen-rich phycobilisomes, resulting in loss of the pigment phycocyanin, a condition which is referred to as bleaching or chlorosis (Krasikov et al. 2012; Hasunuma et al. 2013b). Here, deletion of the $a p c E$ gene caused a decrease in phycobilisomes, similar to observed in response to nitrogen starvation, and hence resulted in glycogen accumulation.

In conclusion, this is the first report that antenna truncation by apcE gene deletion in Synechocystis sp. PCC 6803 increased both biomass production and glycogen content under photoautotrophic and atmospheric air conditions. Due to these properties, this mutant is a potentially useful candidate for use in various biorefinery processes. 


\section{Additional file}

\section{Additional file 1: Primers used in this study.}

\section{Competing interests}

The authors declare that they have no competing interests.

\section{Acknowledgments}

We thank Prof. Masahiko Ikeuchi (Laboratory of Life Sciences, Department of Life Sciences, the University of Tokyo) for providing us with wild-type strain (GT) Synechocystis sp. PCC 6803. This work was conducted with financial support from the Ministry of Education, Culture, Sports, Science and Technology (MEXT) and Core Research for Evolution Science and Technology (CREST), Japan.

\section{Author details}

'Department of Chemical Science and Engineering, Graduate School of Engineering, Kobe University, 1-1 Rokkodaicho, Nada-ku, Kobe, Hyogo 657-8501, Japan. ${ }^{2}$ Core Research for Evolutional Science and Technology, Japan Science and Technology Agency, 3-5 Sanbancho, Chiyoda-ku, Tokyo 102-0075, Japan. ${ }^{3}$ Organization of Advanced Science and Technology, Kobe University, 1-1 Rokkodaicho, Nada-ku, Kobe, Hyogo 657-8501, Japan. ${ }^{4}$ Department of Bioinformatic Engineering, Graduate School of Information Science and Technology, Osaka University, 1-5 Yamadaoka, Suita, Osaka 565-0871, Japan. ${ }^{5}$ RIKEN Biomass Engineering Program, 1-7-22 Suehirocho, Tsurumi, Yokohama 230-0045, Japan. ${ }^{6}$ Precursory Research for Embryotic Science and Technology (PRESTO), Japan Science and Technology Agency, 3-5 Sanbancho, Chiyoda-ku, Tokyo 102-0075, Japan. ${ }^{7}$ Department of Food Bioscience and Technology, College of Life Science and Biotechnology, Korea University, Seoul 136-713, Republic of Korea.

Received: 13 February 2014 Accepted: 18 February 2014

Published online: 15 March 2014

\section{References}

Aikawa S, Joseph A, Yamada R, Izumi Y, Yamagishi T, Matsuda F, Kawai H, Chang JS, Hasunuma T, Kondo A (2013) Direct conversion of Spirulina to ethanol without pretreatment or enzymatic hydrolysis processes. Energy Environ Sci 6:1844-1849

Ajlani G, Vernotte C (1998) Construction and characterization of a phycobiliprotein-less mutant of Synechocystis sp. PCC 6803. Plant Mol Biol 37:577-580

Ajlani G, Vernotte C, DiMagno L, Haselkorn R (1995) Phycobilisome core mutants of Synechocystis PCC 6803. Biochim Biophys Acta 1231:189-196

Akimoto S, Yokono M, Aikawa S, Kondo A (2013) Modification of energy-transfer processes in the cyanobacterium, Arthrospira platensis, to adapt to light conditions, probed by time-resolved fluorescence spectroscopy. Photosynth Res 117:235-243

Bernát G, Waschewski N, Rögner M (2009) Towards efficient hydrogen production: the impact of antenna size and external factors on electron transport dynamics in Synechocystis PCC 6803. Photosynth Res 99:205-216

De Marsac NT, Houmard J (1988) Complementary chromatic adaptation: physiological conditions and action spectra. Methods Enzymol 167:318-328

Ernst A, Kirschenlohr H, Diez J, Böger P (1984) Glycogen content and nitrogenase activity in Anabaeba variabilis. Arch Microbiol 140:120-125

Hasunuma T, Okazaki F, Okai N, Hara K, Ishii J, Kondo A (2013a) A review of enzymes and microbes for lignocellulosic biorefinery and the possibility of their application to consolidated bioprocessing technology. Bioresour Technol 135:513-522

Hasunuma T, Kikuyama F, Matsuda M, Aikawa S, Izumi Y, Kondo A (2013b) Dynamic metabolic profiling of cyanobacterial glycogen biosynthesis under conditions of nitrate depletion. J Exp Bot 64:2943-2954

Izumi Y, Aikawa S, Matsuda F, Hasunuma T, Kondo A (2013) Aqueous size-exclusion chromatographic method for the quantification of cyanobacterial native glycogen. J Chromatogr B 930:90-97

Kaneko T, Sato S, Kotani H, Tanaka A, Asamizu E, Nakamura Y, Miyajima N, Hirosawa M, Sugiura M, Sasamoto S, Kimura T, Hosouchi T, Matsuno A, Muraki A, Nakazaki N, Naruo K, Okumura S, Shimpo S, Takeuchi C, Wada T, Watanabe A, Yamada M, Yasuda M, Tabata S (1996) Sequence analysis of the genome of the unicellular cyanobacterium Synechocystis sp. strain PCC 6803. II. Sequence determination of the entire genome and assignment of potential protein coding regions. DNA Res 3:109-136
Krasikov V, von Wobesser EA, Dekker HL, Huisman J, Matthijs HCP (2012) Time-series resolution of gradual nitrogen starvation and its impact on photosynthesis in the cyanobacterium Synechocystis PCC 6803. Physiol Plant 145:426-439

Li H, Liao JC (2013) Engineering a cyanobacterium as the catalyst for the photosynthetic conversion of $\mathrm{CO}_{2}$ to 1,2-propanediol. Microb Cell Fact 12:4

MacColl R (1998) Cyanobacterial phycobilisomes. J Struct Biol 124:311-334

Melis A (2009) Solar energy conversion efficiencies in photosynthesis: Minimizing the chlorophyll antennae to maximize efficiency. Plant Sci 177:272-280

Nakajima Y, Ueda R (1997) Improvement of photosynthesis in dense microalgal suspension by reduction of light harvesting pigments. J Appl Physiol 9:503-510

Nguyen CM, Kim JS, Hwang HJ, Park MS, Choi GJ, Choi YH, Jang KS, Kim JC (2012) Production of L-lactic acid from a green microalgae, Hydrodictyon reticulum, by Lactobacillus paracasei $\mathrm{LA} 104$ isolated from the traditional Korean food, makgeolli. Bioresour Technol 110:552-559

Page LE, Liberton M, Pakrasi HB (2012) Reduction of photoautotrophic productivity in the cyanobacterium Synechocystis sp. strain PCC 6803 by phycobilisome antenna truncation. Appl Environ Microbiol 78:6349-6351

Polle JEW, Kanakagiri SD, Melis A (2003) tla1, a DNA insertional transformation of the green alga Chlamydomonas reinhardtii with a truncated light-harvesting chlorophyll antenna size. Planta 217:49-59

Rippka R (1988) Isolation and purification of cyanobacteria. Methods Enzymol 167:3-27

Schenk PM, Thomas-Hall SR, Stephens E, Marx UC, Mussgnug JH, Posten C, Kruse O, Hankamer B (2008) Second generation biofuels: high-efficiency microalgae for biodesel production. Bioenerg Res 1:20-43

Shen G, Boussiba S, Vermaas FJ (1993) Synechocystis sp. PCC 6803 strains lacking photosystem I and phycobilisome function. Plant Cell 5:1853-1863

Updegraff DM (1969) Semimicro determination of cellulose in biological materials. Anal Biochem 32:420-424

doi:10.1186/s13568-014-0017-z

Cite this article as: Joseph et al:: Increased biomass production and glycogen accumulation in apcE gene deleted Synechocystis sp. PCC 6803. AMB Express 2014 4:17.

\section{Submit your manuscript to a SpringerOpen ${ }^{\circ}$ journal and benefit from:}

- Convenient online submission

Rigorous peer review

- Immediate publication on acceptance

- Open access: articles freely available online

- High visibility within the field

- Retaining the copyright to your article

Submit your next manuscript at springeropen.com 